\title{
List of reviewers:
}

\section{Ruhuna Journal of Science, Vol. 6 (issue 1 \& 2) 2015}

The list includes also the reviewers contributed for the submitted papers which are subsequently rejected.

Professor Upali S. Amarasinghe, Department of Zoology, University of Kelaniya, Kelaniya, Sri Lanka

Professor Oscar Amarasinghe, Department of Agriculture Economics, University of Ruhuna, Matara, Sri Lanka

Dr. Channa N. Bambaradeniya, IUCN (former), Sri Lanka

Professor M.A.K.L. Dissanayaka, Institute of Fundamental Studies, Kandy, Sri Lanka

Dr. P. Imali N. Fernando, Department of Management Sciences, Faculty of Management, Uwa wellassa University, Sri Lanka

Dr. Thusitha S.L.W. Gunawardana, Dept. of Marketing, Faculty of Management and Finance, University of Ruhuna.

Professor K.B. Suneetha Gunawickrama, Department of Zoology, University of Ruhuna, Matara, Sri Lanka

Dr Chamila Jayasinghe, Department of Food Science \& Technology, Wayamba University of Sri Lanka

Mr. Rohan Pethiyagoda, National Museum, Australia.

Professor R.P.V.J. Rajapakshe, Department of Veterinary Pathobiology, University of Peradeniya, Sri Lanka

Professor E. I. L. Silva, Chairman/CEO, Water Resources Science and Technology (WRST), Colombo, Sri Lanka

Professor Preethi Soysa, Department of Biochemistry \& Molecular Biology, Faculty of Medicine, University of Colombo, Kynsey Road, Colombo 08, Sri Lanka

Professor P. Vinobaba, Department of Zoology, Eastern University, Vantharumoolai, Chenkalady, Sri Lanka

Professor Janak R. Wedagedara, Simcyp-CERTARA Ltd. 2 John Street, United Kingdom S2 4SU

Dr. Deepthi Wickramasinghe, Department of Zoology, University of Colombo, Colombo 3, Sri Lanka

Professor Palitha Wijesundera, Department of Physics, University of Kelaniya, Kelaniya

Professor Wipula B. Yapa, Department of Zoology, University of Colombo, Colombo 3, Sri Lanka 